\title{
El ordenamiento humano del ambiente en el cultivo de mandioca: articulación de conocimientos en la selva paranaense
}

\author{
Human Ordering of the Environment in Manioc Cultivation: \\ Articulating Knowledges in the Paraná Forest
}

\author{
Ana Padawer \\ Universidad de Buenos Aires/Conicet, Argentina
}

\begin{abstract}
RESUMEN
Este trabajo presenta resultados de una investigación etnográfica sobre la articulación de conocimientos prácticos y científicotécnicos del cultivo de mandioca (Manihot sculenta crantz), en contextos rurales interculturales de Misiones, Argentina. Analizo los conocimientos técnicos que se constituyen en un recurso productivo, con énfasis en el ordenamiento humano del ambiente para el crecimiento de la mandioca. Considero las relaciones humanas con el cultivo (selección de variedades) y con el entorno no humano ligado al crecimiento de la planta (suelo, clima y microorganismos) en tres ámbitos de sociabilidad técnica: chacras, asociaciones y organismos técnicos.
\end{abstract}

Palabras clave: conocimiento, tecnología, experiencia, agricultura familiar.
DOI: https://doi.org/10.22380/2539472X.579

\begin{abstract}
This paper presents the results of an ethnographic research on the articulation of practical and scientific-technical knowledge in cassava (Manihot sculenta crantz) cultivation, in rural intercultural contexts of the Misiones province, Argentina. I analyze technical knowledge as a productive resource, with emphasis on the human ordering of the environment for manioc cultivation. I consider human relationships with the crop (selection of varieties) and with the non-human environment linked to the growth of the plant (soil, climate and microorganisms) in three sociability spaces: farms, associations and scientific-technical institutions.
\end{abstract}

Keywords: Knowledge, technology, experience, family farming.

Doctora en Antropología de la Universidad de Buenos Aires (UBA), investigadora del Conicet y profesora de la UBA. Su última publicación es "Temporal Dimensions of Childhood, Youth and Adolescence Experiences: A Conceptual Discussion", Global Studies of Childhood 7-3 (2016): 241-254. apadawer66@gmail.com. 


\section{Presentación}

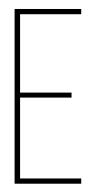

l objetivo de este trabajo es presentar resultados de una investigación etnográfica sobre la articulación de conocimientos prácticos y científico-técnicos en el cultivo de mandioca (Manihot sculenta crantz), atendiendo a sus particularidades en el ambiente de la selva paranaense en la provincia de Misiones (Argentina). La mandioca es una raíz tuberosa de origen americano, domesticada por indígenas, que en términos generales se clasifica en dos grandes grupos: mandiocas dulces y amargas, en función del porcentaje de ácido cianhídrico (ACN) que presenta la variedad. Para su consumo fresco y la extracción del almidón, se requieren técnicas y conocimientos específicos, que se han ido modificando a lo largo de la historia y de la expansión global del cultivo. También se han transformado las formas de producirla, ya que se adapta a condiciones climáticas variadas.

Debido a la importancia de la técnica en la producción de este alimento, reconocido como tradicional, este trabajo tiene como referencia los debates antropológicos que cuestionan, por un lado, la relación entre conocimiento y cultura -y discuten los contrastes entre ámbitos formales e informales, el pensamiento abstracto y el concreto, lo tradicional y lo moderno, la expresión oral y escrita-y, por el otro, la idea de que las culturas son totalidades homogéneas, donde las prácticas sociales se corresponden con modos de pensamiento y cosmologías inconmensurables - y, por lo tanto, sostienen que las culturas indígenas y campesinas son ontológicamente distintas de la cultura científica moderna- ${ }^{1}$.

Este artículo analiza cómo participan los distintos actores sociales en la producción de conocimiento en torno a este cultivo históricamente marginal, que ha adquirido relevancia en las políticas de desarrollo agroindustrial en la selva paranaense durante las últimas dos décadas. El conocimiento acerca de la mandioca se relaciona con los distintos procesos de transformación a partir del trabajo humano, como resultado de dos fines históricos distintos: el cultivo destinado al gasto doméstico (autoconsumo para la alimentación humana y de animales) y la capitalización (venta en el mercado del producto fresco y del almidón). Para ello, me centro en el ordenamiento humano del ambiente, noción que alude a los conocimientos que están implícitos en las prácticas de manejo del cultivo y que resultan imprescindibles para sacarlo adelante. El ordenamiento

\footnotetext{
1 Agradezco a los evaluadores anónimos y editores de la revista los agudos comentarios que permitieron mejorar este artículo, en términos de claridad conceptual y coherencia argumental.
} 
incluye la producción de conocimientos en relación con el cultivo mismo (en especial, en torno a las variedades), así como saberes sobre las relaciones de la mandioca con otros no humanos que inciden en el crecimiento de las plantas (en particular, suelo, clima y microorganismos).

Que el cultivo de la mandioca resulte estratégico en las políticas recientes de desarrollo regional ha implicado que los procesos técnicos utilizados por los productores se vuelvan objeto de intervenciones estatales y estudios especializados. Sin embargo, en Argentina, estos procesos técnicos no han sido abordados antropológicamente hasta el momento porque su importancia económica ha sido marginal en el actual modelo agroindustrial del país, basado en el cultivo de organismos genéticamente modificados en las llanuras centrales.

La provincia de Misiones es la principal productora nacional de mandioca; allí se concentra el 70\% del cultivo del país, en una superficie de unas 40.000 ha. De acuerdo con datos oficiales, tanto para su consumo humano en "fresco", como para su uso forrajero o industrial, es producida mayoritariamente por agricultores familiares, con un promedio de 2,5 ha cultivadas en unas 3.200 unidades domésticas (UCAR 2015).

Como puede verse en el siguiente mapa, en la provincia de Misiones el cultivo de mandioca se concentra en una franja de $200 \mathrm{~km}$ que acompaña el trazado de la ruta nacional n. ${ }^{\circ}$ 12, en la margen izquierda del río Paraná, conocida como la zona tradicional de siembra. Actualmente, el municipio más importante en la producción de mandioca para el consumo en fresco es Gobernador Roca, mientras que los municipios de Puerto Rico y Montecarlo se destacan por la producción destinada a la manufactura de almidón.

\section{Debates conceptuales}

Desde el punto de vista teórico, en este trabajo intentaré conceptualizar las articulaciones de conocimientos sobre el cultivo de la mandioca que se producen en ámbitos domésticos, asociativos y científico-técnicos (СуT), entendidos como tres espacios distintos de sociabilidad técnica (Gras y Hernández 2009). A partir de la idea de redescubrimiento guiado de Tim Ingold (2002), considero que en estos tres espacios de prácticas en torno al cultivo se encuentran los mismos elementos: experiencias sensibles, conversaciones sobre el quehacer y escritura, aunque con una presencia diferencial. 
Figura 1. Mapa de la provincia de Misiones (Argentina)

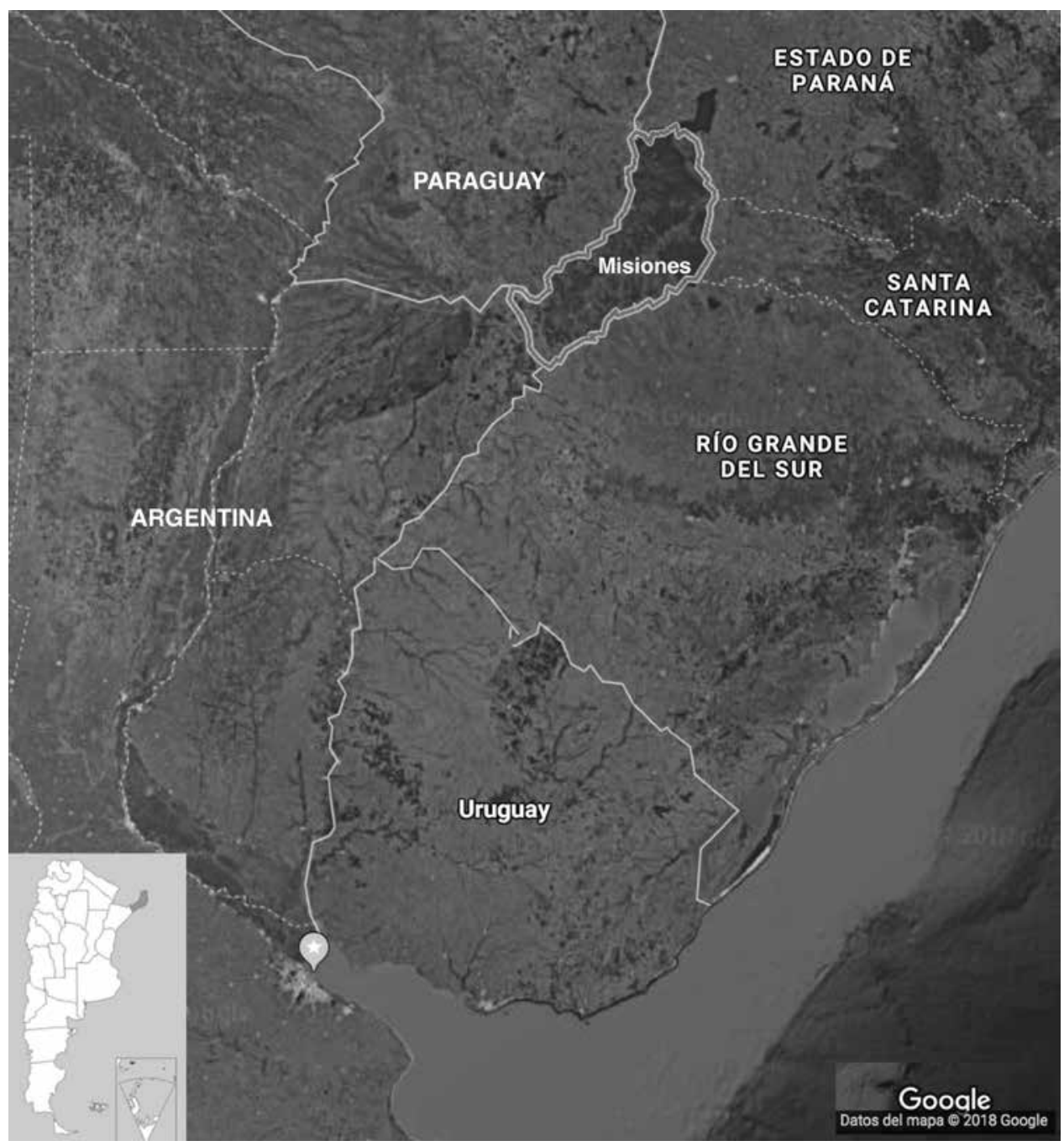

Fuente: elaboración propia con base en Google Maps.

Para fundamentar este enfoque, me remito a un debate que se ha dado en la antropología desde hace por lo menos veinte años en torno a la relación entre conocimiento y cultura. Coincido con quienes cuestionan los esquemas dicotómicos basados en contrastes entre los ámbitos formales e informales de educación, asumiendo correspondencias con el pensamiento abstracto y el concreto (Lave y Wenger 2007), así como con quienes abordan críticamente la oposición entre culturas tradicionales y modernas, y sus correspondencias con la 
expresión oral y escrita (Ellen 2004). En esta discusión ha sido central la revisión crítica del concepto de cultura, en su connotación de totalidades más o menos homogéneas y sostenidas en el tiempo, donde las prácticas sociales se fundamentan - o reafirman - en modos de pensamiento y cosmologías inconmensurables (Rockwell 2005). También ha sido importante la revaluación de la idea del conocimiento como esquemas de pensamiento previos a la acción que luego son “completados” a partir de la experiencia de los sujetos (Ingold 2002).

En este trabajo utilizo las herramientas conceptuales referidas para analizar cómo, en los tres espacios en los que se establece una relación productiva con la mandioca, las experiencias sensibles, las conversaciones sobre las tareas y la escritura se articulan de modo específico en un redescubrimiento guiado, en el que el conocimiento se construye a partir de la información a la que se accede participando junto a aquellos más experimentados en los quehaceres ordinarios (Ingold 2002). Estos tres espacios están vinculados entre sí porque los productores y técnicos establecen relaciones cotidianas (los técnicos visitan los espacios productivos y los productores acuden a las estaciones experimentales), de modo que las prácticas de cultivo derivadas de estas formas de conocer - experienciales, orales y escritas - circulan de un espacio a otro. Siguiendo a Ellen (2004), considero que los conocimientos producidos en los contextos científico-técnicos y tradicionales-prácticos comparten el impulso cognitivo humano de simplificar los procesos mediante los cuales entendemos el mundo²; la caracterización de las articulaciones de experiencias, verbalizaciones y escrituras me permite dar cuenta de las formas concretas e históricas en que el saber técnico se produce socialmente, atravesando distintos espacios institucionales de práctica.

En relación con un debate de escala global que tuvo lugar entre las décadas de los ochenta y noventa del siglo XX, suscitado por la creciente recuperación de conocimientos indígenas tradicionales que originó una reacción cientificista, Ellen (2004) señaló que la categoría conocimiento indígena tradicional no siempre existió. Durante los siglos XVII y XVIII, si bien había prejuicios hacia los conocimientos y las prácticas subalternas, los naturalistas y médicos asimilaban los conocimientos populares y los incorporaban al corpus científico. Estas prácticas se mantuvieron hasta la segunda mitad del siglo XIX, cuando los conocimientos locales comenzaron a ser cuestionados a raíz del desarrollo industrial y de la pretensión, por parte de representantes del conocimiento técnico y científico,

2 Según Ellen $(2004,410)$, las dicotomías entre el conocimiento indígena y el científico son estériles, ya que surgen de una fusión de un impulso cognitivo general de simplificar los procesos por los cuales entendemos el mundo (reforzado por las necesidades de la ciencia de mantener un fundamento de sus prácticas) y la misión occidental de preservar su preeminencia cultural. 
de constituirse en una episteme diferenciada. De acuerdo con este autor, en la segunda mitad del siglo XX se redescubrieron los “conocimientos locales” o "tradicionales”, en una combinación de idealismo romántico y pragmatismo; sin embargo, lo que se originó en ese momento y sigue vigente en muchas posiciones cientificistas, fue la idea de "volver científico el conocimiento tradicional”, reduciéndolo a un artículo/mercancía codificado, seguro y fácilmente transferible.

La discusión sobre las oposiciones epistémicas científicas y populares ha sido extensa, y siguiendo a quienes adhieren a la idea de que en ambos casos se trata de construcciones sociales e históricas (Sousa Santos 2003), recupero aquí las perspectivas agroecológicas de los últimos diez años, que profundizaron en la idea del diálogo de saberes como manera de producir un cambio sustantivo en la forma en que los seres humanos nos apropiamos de la naturaleza (Montesinos y Altieri 1991). Desde este enfoque, el diálogo supone reconocer la legitimidad de los conocimientos tradicionales, pero sin reificarlos: la memoria biocultural, renovada de manera sostenida en mentes y cuerpos a través de generaciones, permite recuperar (y en ese sentido no-ortodoxo, conservar) los sistemas de producción tradicionales; de esta manera, la diversidad genética y paisajística crece desde las culturas concretas (Toledo y Barrera-Bassolls 2008). La idea del diálogo de saberes, que puede ser formulado como un derecho social e individual fundamental (Montesinos y Altieri 1991), no debería conducir necesariamente a una recreación nostálgica de prácticas “ancestrales” e invariantes, sino propiciar que los productores - aun aquellos que ocupan las posiciones más subordinadas- puedan elegir con autonomía sus opciones tecnológicas, dándoles legitimidad a las formas empleadas por generaciones anteriores, y reapropiarse de los recursos genéticos colectados por los bancos nacionales e internacionales en el marco de las investigaciones científicas.

El concepto de mediaciones sociales también aporta a la discusión sobre las oposiciones epistémicas. Esta noción se ha utilizado para dar cuenta de la construcción de espacios públicos de explicitación y confrontación de puntos de vista, formulación de interpretaciones acerca de la vida social, y medios de elaboración de consensos o compromisos aceptados provisoriamente - que implican diálogos desiguales entre agentes con posiciones diferenciadas, expresadas en sistemas de jerarquías reconocidos, y en ocasiones cuestionados (Neves 2010) - Existen numerosos trabajos que han abordado los procesos de mediación social entre técnicos y campesinos en programas de desarrollo, mostrando que el papel de los primeros no puede considerarse como el de meros conectores entre el mundo científico y el campesino, en tanto los propios mediadores construyen e intentan imponer sus perspectivas acerca del mundo. De esta manera, 
aun cuando los mediadores se propongan propiciar la autonomía de campesinos e indígenas, también generan cierta dependencia respecto de aquellos sujetos con quienes trabajan (Cowan 2013). Como veremos más adelante, en Misiones los técnicos agrícolas que trabajan con productores de mandioca no necesariamente se posicionan en un lugar de saber indiscutido respecto de los agricultores, pero los conocimientos que propician raramente son discutidos explícitamente.

Las reflexiones que utilizan las nociones de diálogo de saberes y mediaciones sociales suponen que los sujetos tenemos posiciones y poder diferenciales. En la producción de mandioca que nos ocupa, no solo hay espacios más legitimados que otros (por ejemplo, el sistema de CyT sobre el conocimiento práctico), sino que cada uno de los tres espacios de sociabilidad técnica tiene sus protagonistas centrales y periféricos, en tanto allí se estructuran comunidades de práctica (Lave y Wenger 2007)3. El concepto de participación periférica legítima (Lave y Wenger 2007) me permite identificar situaciones de aprendizaje en torno a la mandioca en su especificidad humana, histórica y social: considerar cómo los novatos, sean los agricultores o los técnicos, adquieren conocimientos en sus experiencias cotidianas a través de la observación y la práctica, que en ocasiones se transmiten mediante la escritura. De este modo, cuando los productores y los técnicos atraviesan los espacios sociales de prácticas que no les son habituales (por ejemplo, un técnico en una chacra ${ }^{4}$ o un productor en una estación experimental), se apropian de formas y objetos de conocimiento como novatos, aunque probablemente en otro espacio sean expertos.

De acuerdo con Lave y Wenger (2007), en cualquier proceso de aprendizaje está implicada inevitablemente la conformación de comunidades de práctica, un proceso social que incluye, de hecho subsume, respecto de la actividad en curso, el aprendizaje de destrezas conocibles. Para poder aprender algo no basta con un corpus de conocimiento y la intención de alguien de enseñarlo; es necesario que los aprendices participen en actividades sociales que incluyen patrones de experiencias comunes y estructurados.

$4 \quad$ En Argentina, las chacras son los espacios productivos agrícolas considerados pequeños (prototípicamente de $25 \mathrm{ha}$ ), donde la mano de obra es esencialmente familiar. 


\section{Aproximación teórico-metodológica al proceso de domesticación de la mandioca en el contexto de estudio}

Inicié esta investigación en el suroeste de Misiones en el 2009. Durante los primeros años trabajé sobre los conocimientos agrícolas de indígenas, pequeños productores y técnicos en torno a las chacras diversificadas. Desde el 2014 el foco del estudio ha sido el cultivo de mandioca, por la importancia estratégica que ha adquirido este cultivo tradicional en los últimos años en la región, aunque en el contexto nacional resulte marginal.

Mediante observaciones y entrevistas abiertas o conversaciones informales en los tres espacios de sociabilidad técnica mencionados (chacras, asociaciones de productores y organismos de CyT), identifiqué que los procesos de producción doméstica de la mandioca abarcaban distintos conocimientos técnicos y que se podían organizar analíticamente en torno a dos dimensiones: a) el ordenamiento humano del ambiente para el crecimiento de la planta (que incluye la reproducción del vegetal y las relaciones con no humanos del entorno) y b) la transformación de la materia radicular bajo la forma de pulpa cocida, harina o almidón. En este trabajo me detendré exclusivamente en la primera dimensión, a fin de considerar en detalle cómo se producen los procesos de articulación de experiencias, conversaciones y escritura en los tres espacios de prácticas más relevantes.

El ordenamiento humano del ambiente para el crecimiento de la mandioca está inscrito en relaciones o regímenes de familiaridad con el cultivo en sentido estricto, así como con los no humanos que constituyen su entorno hasta tanto este sea cosechado; el hecho de ser un cultivo doméstico implica que los seres humanos reactualizan relaciones de dominio sobre la planta, establecidas históricamente, al manejar su reproducción y crecimiento (Schiavoni 2015). Las relaciones con la planta incluyen la selección de variedades y su reproducción a través de esquejes o ramas (es decir, una clonación doméstica), y las relaciones con el resto de los no humanos que incluyen: el suelo y el clima (formas de relieve y precipitaciones, clima y conservación de simientes, y fertilización), la vegetación copartícipe (aprovechamiento de cultivos asociados) y la competente (control de malezas), y los animales, insectos y microorganismos (especialmente virus, bacterias y hongos).

En Argentina, estos regímenes de familiaridad/domesticidad se configuran de modo particular en las chacras, las asociaciones de productores y los 
organismos de CyT agrícola. Las chacras fueron resultado de procesos de expansión de la frontera agraria que se desarrollaron especialmente entre fines del siglo XIX y la primera mitad del siglo XX, y en algunas zonas del país dieron origen a la categoría de “colonos” - para denominar a quienes se asentaron en los nuevos territorios-, un término de identificación con plena vigencia en Misiones (Bartolomé 2007). En este proceso histórico, a partir de la década de los treinta, las asociaciones de productores en esta región adquirieron la forma de cooperativas agrícolas de colonos y se desarrollaron inicialmente centradas en el cultivo de yerba mate (Gallero 2013) y, en los últimos años, en torno de la mandioca. Finalmente, las instituciones estatales y las universidades son los organismos de CyT que se vincularon más recientemente a este cultivo. Sin embargo, el organismo más importante de intervención tecnológica directa con los productores agrícolas ha sido y continúa siendo el Instituto Nacional de Tecnología Agrícola (INTA), creado a mediados del siglo XX5 (INTA 2017).

La selva paranaense es un ambiente productivo marginal en el complejo agroindustrial argentino: se trata de una zona subtropical sin estación seca, que históricamente fue disputada con Paraguay y Brasil. Por esas disputas, a fines del siglo XIX el Estado organizó planes de colonización, en los cuales se desarrolló el cultivo de yerba mate (Ilex paraguarensis), de origen indígena, con la que se elabora la infusión de consumo más popular del país. Los colonos producían yerba y otros cultivos para su subsistencia, y adoptaron de los indígenas mbyàguaraníes el cultivo de mandioca, que se integró a la alimentación cotidiana. Estos colonos conformaron las primeras cooperativas agrícolas con las que se vinculan actualmente los técnicos gubernamentales para el desarrollo de mejoras en los cultivos.

Resumo en el siguiente esquema este proceso de domesticación. En el cuadro central incluyo las dos dimensiones de ordenamiento del ambiente a considerar: las relaciones con el cultivo y con los no-humanos. Subrayo la primera de las dimensiones, ya que el hallazgo principal del estudio ha sido lo que denominaré el problema de las variedades. Este se vincula con la reproducción clonada de la mandioca que realizan los productores en Misiones debido a las condiciones climáticas, lo que tiene consecuencias en las relaciones que se establecen con los otros no humanos en torno al cultivo. En los tres cuadros que lo rodean, incluyo los ámbitos de sociabilidad técnica en los que se producen estos conocimientos,

$5 \quad$ El INTA se creó en 1956, con la finalidad de "impulsar, vigorizar y coordinar el desarrollo de la investigación y extensión agropecuaria y acelerar la tecnificación y el mejoramiento de la empresa agraria y de la vida rural" (INTA 2017). Actualmente, depende del Ministerio de Agroindustria y está conformado por centros regionales, estaciones experimentales, institutos de investigación y unidades de extensión. 
subrayando la forma predominante de producción de conocimiento (experiencial, conversacional y escrito) en cada uno de ellos. También incluyo, entre paréntesis, una breve caracterización de las formas concretas que asume cada una de las formas en los tres espacios. Como puede verse, se trata de énfasis distintos pero ninguno de los tres ámbitos carece por completo de las formas de conocimiento que están presentes en los otros.

A partir de estas consideraciones y siguiendo el esquema, el análisis que sigue a continuación está organizado en dos partes: en la primera describo los espacios de sociabilidad técnica en el contexto de estudio y en la segunda explico cómo se presentan los conocimientos sobre el ordenamiento del ambiente para la producción de mandioca en dichos espacios, atendiendo a las relaciones con el cultivo y con el entorno no-humano.

Figura 2. Ordenamiento del ambiente y ámbitos de sociabilidad técnica en torno a la mandioca

Ámbitos asociativos. Redescubrimiento guiado protagonizado por agricultores y técnicos, mediado por:

- Experiencias sensibles (uso de sentidos en el proceso de cultivo)

- Conversaciones sobre las tareas (en reuniones)

- Escritura (registros diarios de quehaceres y uso de manuales)

\section{Ámbitos domésticos.}

Redescubrimiento guiado protagonizado por agricultores, mediado por:

- Experiencias sensibles (uso de los sentidos en el proceso de cultivo)

- Conversaciones sobre las tareas (atención cotidiana al cultivo)

- Escritura (registro diario de quehaceres y uso de manuales)

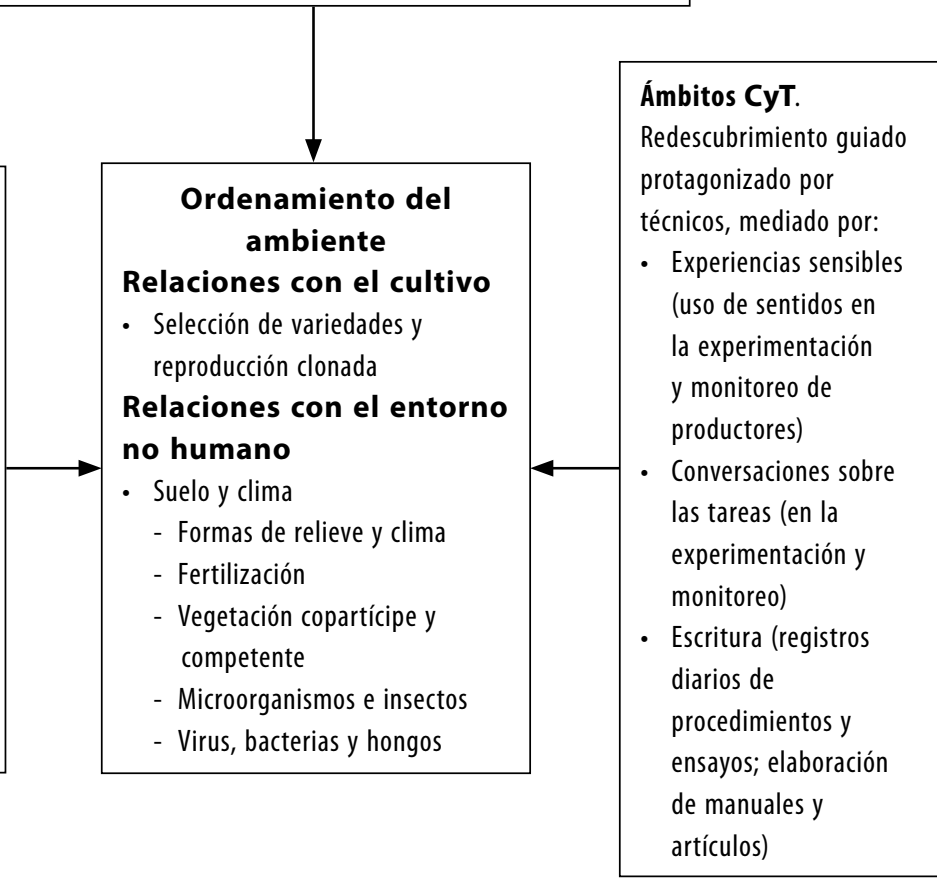

Fuente: elaboración propia. 


\section{Actores y espacios de sociabilidad técnica sobre la mandioca en Misiones}

Los espacios rurales de la provincia de Misiones tienen una larga historia de relaciones interculturales, donde conviven actualmente comunidades indígenas mbyà-guaraníes y familias criollas ${ }^{6}$. Estas últimas se autoidentifican como "gente de la colonia”, por ser descendientes de aquellos europeos que participaron en la colonización estatal y privada de la primera mitad del siglo XX (Bartolomé 2007; Bartolomé 2009). Como hito fundante de esas relaciones interculturales, los jesuitas establecieron en el sur de la provincia sus reducciones de indios en el siglo XVII y permanecieron allí hasta su expulsión en $1767^{7}$. A partir de ese momento, la población criolla fue ocupando ese territorio lentamente, con mayor intensidad al finalizar la guerra de la Triple Alianza ${ }^{8}$. En 1881, el actual territorio de Misiones fue declarado territorio nacional. Este hecho político formó parte de un proceso de afianzamiento de los límites fronterizos encabezado por el Estado, que se complementó con la creación de colonias agrícolas de inmigrantes (Bartolomé 2007).

Dentro de las poblaciones guaraníes actuales, los mbyà se distinguen porque utilizan el mismo etnónimo en los distintos países en los que viven, ya que quienes se identifican como parte de este colectivo se reconocen como descendientes de aquellos indígenas guaraníes que lograron permanecer al margen de las reducciones, mediante la constitución de pequeñas comunidades refugiadas en la selva (Bartolomé 2009). Dado que el establecimiento de los mbyà en el actual territorio argentino se definió en relación con el avance de las fronteras del poblamiento agrícola criollo, tanto la colonización en la primera mitad del siglo XX como el desarrollo del extractivismo maderero en las últimas décadas provocaron cambios sustantivos: de las aldeas mbyà-guaraníes se desprenden de modo permanente grupos de familias que conforman nuevas poblaciones o se

6 En Argentina se denomina criollos a los descendientes de españoles e indígenas. Se trata de una categoría de autoidentificación asociada a la nacionalidad que atraviesa toda la historia posterior a la Conquista y colonización y llega a la actualidad.

7 La información histórica sobre la población indígena en Misiones está estrechamente vinculada a la documentación que proviene de las reducciones jesuitas. Sin embargo, los estudios arqueológicos ubicaron poblaciones que comparten rasgos materiales definidos como guaraníes en un amplio territorio que abarca Paraguay, el sur del Brasil y el noreste de Argentina, desde por lo menos 2000 años a. P. (Da Silva Noelli 2004).

8 A raíz de este conflicto, que tuvo lugar entre 1865 y 1870, se demarcaron las fronteras nacionales entre Argentina, Brasil y Paraguay. 
integran en otras preexistentes en función de la tierra cada vez menos disponible (Gorosito 2010).

Los mbyà-guaraníes en Misiones tienen una importante tradición de consumo de mandioca fresca (mandi’o) y también de elaboración de alimentos con base en el almidón: la planta está presente en narraciones culturales que explican su origen, recreadas incluso en libros de texto escolares (Ministerio de Educación de la Nación 2015). Como resultado de las relaciones interétnicas en Misiones, los criollos adoptaron el consumo de la mandioca fresca y la manufactura de almidón en las chacras. El producto primario pasó a formar parte de la alimentación en las unidades domésticas, mientras que su transformación en derivados como el almidón o la harina, aun con una elaboración artesanal o mecanización precaria, posibilitó cierta capitalización de los agricultores (Gallero 2013).

Los cultivos industriales en esta provincia incluyen principalmente la yerba mate, el té y el tabaco, pero la mandioca se diferencia de los anteriores por tratarse de un producto central para las políticas alimentarias, ya que sus raíces tuberosas son una importante fuente de hidratos de carbono, y tanto estas como sus partes aéreas pueden utilizarse también para la alimentación animal, además de sus usos industriales como almidón y harina (Ministerio de Agricultura, Ganadería y Pesca 2015). Por estas cualidades, la mandioca ocupa actualmente un lugar de importancia creciente en los programas sociales de desarrollo destinados a pequeños productores agrícolas, quienes tienen chacras diversificadas orientadas al autoconsumo. Además de mejoramientos de la producción en términos de seguridad alimentaria, estos programas se proponen el valor agregado de un cultivo que es reconocido como tradicional y, por lo tanto, está presente en todas las unidades domésticas (Padawer 2016).

En nuestro trabajo de campo identificamos que, en las chacras de criollos y de indígenas, las relaciones de sociabilidad técnica sobre la mandioca se dan mediante la incorporación de los distintos integrantes del grupo familiar en la producción, por lo que las chacras son escenarios centrales de comunidades de práctica para el conocimiento del cultivo. Allí se despliegan las habilidades diferenciales logradas progresivamente por los adultos y los hijos varones de las unidades domésticas ${ }^{9}$ (mujeres y niñas ocupan posiciones más periféricas), quienes definen dónde y cuándo se realizarán las plantaciones, cómo se conservarán las ramas-semillas, etc. Como lo he desarrollado en otro trabajo (Padawer 2015), en

9 Si bien las mujeres y las niñas ocupan un lugar más periférico en la organización de los cultivos en las chacras, las mujeres desempeñan un papel importante en la selección y manejo de las variedades por sus distintas ventajas culinarias y características organolépticas, conocimientos e ideas que se transmiten en los espacios domésticos y en las cocinas, y que circulan indirectamente en espacios públicos. 
las chacras el conocimiento proviene centralmente de habilidades articuladas desde la experiencia sensible: las generaciones jóvenes se incorporan a los quehaceres siguiendo los pasos de los más experimentados (Ingold 2002). En estos casos, las explicitaciones verbales son complemento de la acción, mediante traducciones fundadas en habilidades que se ponen en juego, especialmente con las visitas de los técnicos: sensaciones sobre la humedad del suelo son traducidas en niveles de humedad, partes de las plantas reciben nombres equivalentes para que puedan ser entendidas por distintos interlocutores, de acuerdo con el contexto (Padawer 2015).

La mandioca es actualmente una de las principales líneas de trabajo de los organismos técnicos gubernamentales en los programas de fomento de la horticultura en Misiones. Además del acompañamiento en la producción, han incentivado la comercialización a través de la promoción de las Ferias Francas y mercados concentradores, que tras la recuperación democrática a principios de los años ochenta, capitalizaron la experiencia asociativa de los movimientos sociales rurales de la provincia, desarrollados en la década de los setenta ${ }^{10}$. Como han señalado investigaciones efectuadas en otros contextos, las asociaciones de productores agrícolas ocupan un lugar de relevancia como espacios de sociabilidad técnica en Argentina, ya que propician espacios para conversar sobre los quehaceres en un marco de confianza, lo que facilita la traducción del sistema experto en el lenguaje de las prácticas (Gras y Hernández 2009).

Mi trabajo de campo mostró que estos espacios de sociabilidad técnica se presentan en cooperativas y en una organización de segundo nivel, el Clúster de la Mandioca Misionera, creado en el $2013^{11}$. Este clúster es de gran interés por la heterogeneidad de actores implicados, ya que allí se reúnen las cooperativas (integradas por colonos), empresarios familiares (colonos más capitalizados), funcionarios públicos de gestión agrícola (nacionales, provinciales y

10 Las Ferias Francas son mercados donde los productores comercializan directamente sus productos. Fueron creadas en 1995, por quienes habían participado en el Movimiento Agrario Misionero (MAM) antes de la dictadura militar. El MAM se fundó en 1971 luego de una crisis del sector yerbatero y fue disuelto por las autoridades militares. A diferencia de otras provincias, donde los movimientos sociales agrarios de la época focalizaron sus demandas en la tenencia y distribución de la tierra, las reivindicaciones fundantes del MAM se centraron en cuestiones referidas a la producción y sobre todo a la comercialización de sus productos (Galafassi 2008).

11 El Clúster de la Mandioca Misionera es una entidad de segundo grado que reúne a cooperativas, empresas familiares, organismos técnicos y universidades, auspiciado por el Ministerio de Agroindustria de la Nación, como parte de una política de desarrollo mediante clústeres y microrregiones. Es una institución que canaliza financiamiento estatal y busca solucionar, en conjunto, los problemas que afectan a los productores especializados en este cultivo. 
municipales) y de CyT (en este caso el INTA, el Instituto Nacional de Tecnología Industrial [INTI] ${ }^{12}$ y las universidades ${ }^{13}$ ).

Cooperativas y clúster son escenarios de mediación social (Cowan 2013; Neves 2010); espacios donde se desarrollan comunidades de práctica que permiten la incorporación progresiva de habilidades técnicas, donde productores y técnicos ocupan posiciones más centrales o más periféricas dependiendo de la actividad en cuestión (Lave y Wenger 2007). Aquí tienen un lugar central las conversaciones que se establecen en las reuniones periódicas, donde un productor que ha realizado un ensayo de uso de una cosechadora puede relatar qué problemas se le presentaron, o se comentan imágenes tomadas con un celular sobre una nueva plaga que ha aparecido en un campo. Asimismo, se llevan a cabo demostraciones prácticas, llamadas jornadas a campo, en las que los técnicos muestran algunos ensayos efectuados de manera colaborativa con los productores en sus chacras, cuando esos encuentros no se realizan en las estaciones experimentales mismas ${ }^{14}$.

Mediante su participación en el Clúster de la Mandioca Misionera, los técnicos del INTA canalizan un trabajo que realizan desde hace décadas con los productores, orientado principalmente a mejorar el cultivo: para ello elaboran manuales, efectúan ensayos en centros experimentales y asisten a las chacras in situ por medio de las oficinas de extensión rural. Su producción de conocimiento sobre el cultivo ha girado en los últimos tiempos en torno a la identificación molecular de las variedades de mandioca, ensayos de fertilizantes y herbicidas, métodos de conservación en fresco e identificación de microorganismos que afectan a la mandioca de uso industrial. El INTI, por su parte, ha realizado estudios sensoriales de variedades y certificaciones de buenas prácticas de manufactura.

El INTI, creado en 1957, tenía como objetivo "facilitar y articular el conocimiento científico y técnico aplicado a la producción y transferirlo a los actores productivos públicos y privados". Actualmente, el organismo está organizado en centros regionales y multipropósito, que trabajan en las áreas de construcción, materiales y procesos, electrónica y metrología, hidrocarburos, química, y recursos naturales y medio ambiente (INTI 2017).

Las universidades trabajan en proyectos puntuales de modo incipiente, razón por la cual no las hemos considerado en el artículo. En el caso de la mandioca misionera, se han vinculado investigadores ligados a los biomateriales y la ingeniería mecánica, la genética, la maquinaria agrícola y la ingeniería en alimentos.

Si bien no me detendré en esta cuestión, el trabajo de campo me permitió identificar que las cooperativas y las empresas son los espacios preferenciales de sociabilidad técnica en torno al almidón de mandioca, ya que en pocas chacras se continúa con la elaboración de almidón artesanal. Según los estudios oficiales del sector, un $25 \%$ de la producción de mandioca en Misiones se destina al uso industrial: el principal producto elaborado es la fécula (o almidón), que se comercializa como "almidón nativo" para consumo humano y también como "almidón modificado", que se utiliza como aglutinante en alimentos, panificados, textiles, papeleras, adhesivos y químicas (UCAR 2015). 
Cada uno de estos espacios institucionales de CyT puede ser analizado a partir de la noción de comunidades de práctica, ya que en los laboratorios y oficinas de extensión hay marcadas relaciones de novatos y expertos (Lave y Wenger 2007). Por razones de espacio, me enfocaré en las relaciones de interlocución con los productores, en las cuales los investigadores comparten sus resultados mediante conversaciones en las asociaciones, el clúster, las jornadas a campo y algunas publicaciones de divulgación.

\section{El ordenamiento del ambiente para el cultivo de mandioca y sus dimensiones: relaciones con el cultivo y con el entorno no humano}

Schiavoni (2015) inició los estudios en torno al ordenamiento del ambiente de la mandioca por parte de los pequeños productores en Misiones, advirtiendo la importancia de profundizar en su articulación con el aparato tecnocientífico involucrado en el proceso de domesticación. Esta autora subrayó que para los pequeños agricultores la mandioca dulce era un cultivo tradicional de subsistencia, es decir, un alimento destinado al autoconsumo que generaba autonomía para la reproducción del grupo doméstico, aprovechando el potencial reproductivo disponible (en este caso, las ramas). El conocimiento de los agricultores y los técnicos de los programas estatales agrarios se fue articulando durante todo el siglo $\mathrm{XX}$, y se intensificó en las últimas décadas cuando la mandioca se integró en las políticas de fomento a la horticultura. De esta manera, el tubérculo se convirtió progresivamente en un alimento-artefacto, en el que las plantas de mandioca dulce eran mejoradas y, por ende, transformadas en sustancia, pero también en sus relaciones con los humanos.

El ordenamiento del ambiente para el cultivo de mandioca que Schiavoni (2015) sistematizó incluyó especialmente el registro de vínculos de familiaridad en las chacras: redes entre humanos y no humanos con expresiones simbólicas tales como las homologías de partes de la planta con partes humanas, o a partir de prácticas agrícolas, por ejemplo la producción a granel, aprovechando que "la mandioca espera al productor debajo de la tierra”, pues se conserva hasta dos años. Si bien la autora no profundizó en este aspecto, en su estudio advirtió que la transformación del cultivo en un alimento de venta en el mercado implicaba 
la intervención del aparato tecnocientífico del desarrollo, lo que engendraba un nivel de domesticidad distinto al del autoconsumo, en el que las relaciones de dominio de la naturaleza eran más marcadas (de ahí la idea de alimento-artefacto). A partir de estas investigaciones pioneras en Argentina, me propuse abordar estos aspectos que han sido menos estudiados hasta ahora.

La constitución de la mandioca como objeto-artefacto ha implicado cambios en la incorporación de trabajo humano en el ordenamiento del ambiente; dado que se trata de una planta domesticada en Sudamérica desde hace por lo menos 3.000 años, necesariamente las condiciones de vida de agricultores y cultivares se han transformado en una mutua interacción o coevolución (Pujol et al. 2007) ${ }^{15}$. A continuación analizaré el conocimiento producido en la actualidad sobre la mandioca en chacras, asociaciones y organismos de CyT en Misiones, estudiando los dos componentes básicos del ordenamiento del ambiente: las relaciones con el cultivo y con el entorno no humano.

\section{Relaciones con el cultivo: el conocimiento de las variedades}

Las relaciones de familiaridad en torno a la mandioca se definen, especialmente, a partir de su versatilidad. Debido a que se trata de un cultivo multipropósito, el vínculo que el agricultor establece con la planta depende del tipo de producto que se pretende obtener. Por ello, en las relaciones humanas con el cultivo, me detendré en el conocimiento que permite la selección de variedades. Este es un proceso clave, principio de un encadenamiento de relaciones de cuidado para que la planta se desarrolle; a partir de allí interviene además el vínculo con otros no humanos, por lo que estas relaciones subsecuentes se abordarán en el apartado siguiente.

Además de cambios en el ordenamiento del ambiente para el crecimiento, también ha cambiado el trabajo humano en torno a su reproducción, mediante métodos de propagación clonada (en chacras y laboratorios) y estrategias de ampliación de la diversidad a partir de la reproducción sexuada de semillas (Emperaire y Peroni 2007; Rival 2001; Rival y Mckey 2008). Asimismo, ha cambiado el trabajo humano en torno a los procesos de transformaciones de las raíces tuberosas con fines alimenticios e industriales, lo que ha derivado en que ciertas variedades predominen sobre otras (Altenfelder 2016). Ambiente de crecimiento, reproducción y transformaciones de raíces tuberosas se encuentran estrechamente vinculados pero, como lo he anticipado, en este trabajo me enfocaré en el primer aspecto, y mencionaré los otros de modo indirecto. 
En la definición del propósito con el que los humanos cultivan las distintas variedades de la mandioca, la presencia relativa de ácido cianhídrico (ACN) define su aptitud para el consumo fresco o modificado, dando lugar a la distinción entre mandiocas dulces y amargas, como una gran clasificación de sus variedades en todo el mundo (Rival 2001). En Misiones los productores cultivan exclusivamente mandiocas dulces, pero entre ellas también resulta importante identificar variedades, porque los porcentajes de almidón y ACN difieren, y por lo tanto su calidad para fines industriales o de autoconsumo puede ser más o menos apreciada. La selección de variedades también se vincula con las relaciones con no humanos, especialmente con la vegetación competente y los microorganismos, como veremos luego: la identificación de variedades es fundamental para el ordenamiento del ambiente, ya que saber qué cultivares se están plantando, en qué lugar y en qué momento, permite anticipar la productividad, la resistencia a las enfermedades y la calidad culinaria de lo sembrado:

Darío: vos tenés 57 parámetros morfológicos de descripción para la mandioca. Por ejemplo, se considera el largo del pecíolo, su color [...]. Es lo que se usa para hacer la descripción en el Inase [Instituto Nacional de Semillas]. El primer cultivar que describimos en Argentina es el paraguaya CA [...]. Este clon vendrá de algún productor de Paraguay, de ahí el nombre, y es para consumo fresco. Sirve registrar porque si no viene una persona o un instituto de afuera y les puede pedir a todos los productores que la hacen que les pague patentes por ese cultivo. (Conversación con técnico en la estación experimental, marzo del 2017)

El registro morfológico mencionado por el técnico es claramente un conocimiento anclado en los registros escritos (protocolos del Inase), pero se asienta en la capacidad de observación y la experiencia sensible, en especial, a partir de la capacidad visual. La inscripción incipiente de la que da cuenta el técnico se vincula con que la mandioca es un producto agrícola de valor comercial marginal en Argentina, por lo que los estudios en CyT aquí son escasos. En particular, las investigaciones se enfocan en las variedades de mandioca de uso industrial, no en las de consumo doméstico, ya que generan mayor interés en los productores capitalizados que financian los estudios de CyT directamente o a través del fomento estatal.

En la identificación incipiente de variedades también incide su propagación clonada, vía esquejes o ramas, que se conservan y se intercambian entre productores, incluso transnacionalmente. De esta manera, un productor trae de una chacra o de un evento asociativo una variedad que considera nueva, que otros productores vecinos cultivan bajo otra denominación. En los testimonios que siguen, la identificación de variedades se produce por un redescubrimiento guiado, que es fundamental para saber con qué mandioca se está interactuando. 
En ese redescubrimiento guiado, proceso de por sí heterogéneo, los productores y técnicos van educando la atención para identificar ciertos detalles y así poder nominar al cultivo: el color del tallo, la forma de las hojas, el tamaño, la forma y color de las raíces son indicios de nombres que se aprenden realizando las tareas en la chacra o conversando con quienes proporcionan las ramas, en el caso de los productores; leyendo manuales e informes que los describen, en el caso de los técnicos. Estos aspectos perceptivos se condensan en registros orales sobre las variedades que se han plantado en cada cuadro en las chacras anualmente, mientras que en las estaciones experimentales se registran mediante la escritura: dado que hay decenas de variedades en las colecciones de las estaciones experimentales, los técnicos pueden identificar de modo sensorial solamente aquellas parcelas donde están realizando sus ensayos; para el resto de la colección apelan a informes escritos.

La selección de variedades de mandioca dulce tiene, tanto en familias de indígenas mbyà como de criollos, un principio ligado a la producción de alimentos y el consumo en fresco. Las variedades preferidas son conocidas con los nombres criollos de coloradita, rocha, blanca, concepción, pombero guazú y amarilla, entre otras, y en el caso de los mbyà, como mandi'o karape, mandi'o pyta, mandi'o michy, mandio' hu:

Andrés: de la mandioca también se perdió bastante porque teníamos mandi'o karape, que es la más chiquita, petisa, no llega a medio metro, en época de mi suegro ellos tenían [...]. Mandi’o pyta es colorada, mandi'o chy es más chiquita. Este año tuve algunas plantas de esas. La negra es más grande la raíz, mandio’ hu, esa todo el tiempo se cocina. La blanca [se refiere a la criolla] hay un momento que no se puede cocinar. [...] Yo no sabía de la chacra, pero tuve que aprender. Mi suegro me pedía: “¿Sabes hacer la chacra?”. Y ahí yo me iba a aprender a las comunidades, si no no me dejaba casar. Pero no era solamente por él, era por ella. A Raquel le gusta la chacra, cuando está medio en capuera [monte] ella está triste. (Conversación con productor, comunidad mbyà de Katupyry, San Ignacio, diciembre del 2016)

Miguel: yo planto distintas variedades de mandioca. Una que le dicen rocha, la verde olivo, la mandioca blanca y la negra (que le dicen Petroski); una que le dicen catalinense y la blanquita de antes, que está desapareciendo. La blanquita era la preferida de toda la vida, pero hoy en día prefieren de lo que se cría más rápido, más grande, y entonces traen de Brasil las ramas. [...] La blanquita también tiene más resistencia: será porque es planta natural de acá, para mí es mejor. Las de allá vienen con pestes, que sé yo... La verde olivo se le acerca a la blanquita en el sabor, pero el rendimiento es mejor. [...] Si uno planta verde olivo para mayo o junio, para las fiestas uno ya tiene para cosechar. [...] Lo que des- 
cubrí es que la verde olivo es una planta es que tiene la raíz superficial. Entonces las lluvias de fin de año absorben fácil y así se cría. La catalinense tiene raíz profunda, entonces en enero, con el sol, la verde olivo deja de crecer, y la catalinense recién en ese momento empieza de crecer. Entonces, cuando una deja de crecer, empieza la otra. (Conversación con un productor en la chacra, Gobernador Roca, diciembre del 2016)

Como surge de los testimonios de Andrés y Miguel, estas variedades dulces son valoradas por su uso culinario en fresco, pero las susceptibilidades a enfermedades - en lo que detectan cambios a lo largo del tiempo-y el ritmo de crecimiento también son importantes. Estos aspectos son observados por los productores - como el descubrimiento de Miguel respecto de la profundidad de las raíces de la variedad verde olivo con relación a la catalinense y su interacción con el clima-, y a la vez están siendo estudiados por los técnicos, como explicaré luego, en particular para el caso de las variedades que se destinan también a almidón. A diferencia de las variedades domésticas, identificadas con los nombres de personas que las circularon o por las características fenotípicas, las mandiocas dulces almidoneras generalmente tienen un nombre que combina letras y números, remitiendo al centro de investigación que las identificó, aunque también circulan de modo informal, de mano en mano:

Gastón: la que plantan más acá en la cooperativa es CA 25 viene de Cerro Azul, de la oficina del INTA, donde hubo un mejorador genético que hizo esa selección. [...] Yo acá estoy promocionando la IAC 90 porque tiene pocas fallas: la idea es conseguir 10.000 plantas por hectárea. El productor con otras variedades por ahí consigue 6.000 o 7.000, hay muchas estacas que son plantas muertas; mientras que la IAC 90 es muy noble, en el sentido de que la rama se banca mucho el traqueteo, estaca que tiras sale la planta. Además tiene una velocidad de crecimiento mucho mayor: te cubre antes el suelo, te hace sombra, entonces evita que salgan malezas [...]. IAC es el Instituto Agronómico de Campinas, es una variedad brasilera, alguien habrá traído una vez tres o cuatro ramitas y así se difundió, porque es muy común que los productores se pasen ramas. Los productores traen de jornadas especiales que se hacen sobre mandioca pero también porque pasan por un camino, ven una planta que les gusta y piden. (Gastón, técnico de una cooperativa en oficina del INTA, junio del 2016)

Esteban: hicimos un proyecto de análisis de variedades, porque acá hay variedades que se hacen para comer en fresco, otras para almidón, pero hay más de mitos urbanos y conocimientos de lo que se supone que es mejor, no había nada químico, ningún fundamento bien técnico. [...] Nosotros probamos seis variedades almidoneras y seis de fresco. La gente 
del INTA nos prestó su ensayo para extraer las muestras: fuimos a cosechar una vez al mes, las pelamos, las cortamos, las secamos y las convertimos en harina. Después medimos la relación amilosa-amilopectina, que son las dos macromoléculas que componen el almidón. Con eso vos podés ver si la variedad es cocinable, si sirve para industria. [...] Después hicimos una prueba de análisis sensorial, cosechamos todas las mandiocas de doce meses y las pusimos sobre una mesa, industriales y no industriales, y se las hicimos probar a la gente, y no pudieron discriminar grandes diferencias. Entonces muchas veces la gente dice que prefiere una porque tiene un nombre, más que otra cosa. [...] por ahí te dicen que prefieren la rocha porque es la más rica para comer, pero entre dos o tres no la pueden distinguir. Por ahí son más arenosas, sí tienen más almidón, pero no es que no se puede comer, es que no es tan rico. Y si las cocinas bien, yo creo que no se nota. (Esteban, técnico del INTI, conversación en Posadas en diciembre del 2016)

En el testimonio de Gastón, la descripción técnica de la variedad preferida incluye registros de la velocidad de crecimiento (que además vincula con la reducción de tareas de eliminación de vegetación competente), a la que agrega cuantificaciones de la efectividad del brote: si bien la variedad es descrita con cualidades o atributos humanos —es más "noble"-, la relación de dominio en una producción a escala industrial está definida por la contabilización precisa de cultivares por hectárea, a partir de la cual este técnico cuestiona las decisiones de los productores basadas en otros parámetros distintos a la eficiencia. En el testimonio de Esteban hay una recuperación de las formas de conocimiento experiencial de las variedades —-son más arenosas-; pero se destaca su confirmación de que la composición química es la forma más eficaz para identificar variedades que resultaban indistinguibles en los ensayos sensoriales. Su testimonio es evidencia de la construcción social del gusto (Bourdieu 2002): en este caso, las variedades más apreciadas en la culinaria se forjan a partir de ciertos nombres que circulan entre los productores, quienes identifican aquellas mandiocas que se “cocinan mejor”. La descripción detallada del procedimiento de análisis forma parte de su comunidad de práctica de CyT: la interlocución cotidiana de Esteban con productores hace que traduzca estos términos a un lenguaje coloquial — “las pelamos”, "las cortamos”-; aunque al mismo tiempo incluya definiciones y jerga - la relación amilosa-amilopectina-que marcan su espacio de sociabilidad técnico-específico. A continuación, presentaré los conocimientos vinculados al entorno no humano, procurando también mostrar las articulaciones que se dan en los distintos espacios de sociabilidad técnica. 


\section{Relaciones con el entorno no humano: el suelo y el clima}

Como he señalado, el conocimiento producido en las chacras para el ordenamiento del medio ambiente en torno a la mandioca se basa en el redescubrimiento de habilidades corporales (Ingold 2002). Los adultos y jóvenes varones son quienes generalmente deciden el manejo del suelo en las chacras: para ello deben entrenarse en observar las formas del relieve, especialmente las pendientes que facilitan el drenaje en épocas de altas precipitaciones, como puede verse enseguida en el testimonio de Julio y de Alejandro. Esa observación es una tarea individual y colectiva: las chacras se organizan progresivamente a lo largo de generaciones, por lo que el uso previo del espacio en plantaciones perennes o el rendimiento anterior en plantaciones anuales son puntos de partida para definir los cuadros en los que cada año se divide la chacra para la siembra de cada cultivo.

A partir de la observación de la pendiente, de los esquemas mentales sobre la organización previa de la chacra, así como del registro experiencial y oral de rendimientos previos, en cada chacra se destinan espacios para la mandioca nueva, que es la que se va a consumir en el primer año, y por lo tanto puede ubicarse en terrenos más bajos; la mandioca vieja, que se reservará en la tierra hasta un año más, debe ubicarse a más altura. En el caso de los mbyà, la mandioca está integrada a la organización de la huerta, junto con otros cultivos destinados al autoconsumo; en el caso de los criollos, la huerta no se define en sí misma sino en función de las plantaciones perennes que organizan la chacra durante generaciones:

Julio: acá tengo unas mil plantas de mandioca, trasplantar me llevó dos días. Me ayudaron mis dos hijos más grandes, mi señora. Más allá hay maíz, melón, sandía [...] Esta es mandioca nueva, y más allá arriba está la vieja, la planta del año pasado, cocina lindo y las plantas son más grandes. (Conversación con un productor en la comunidad mbyà Andresito, octubre del 2014)

Alejandro: esta chacra tiene 50 hectáreas. Planté 10 hectáreas de pinos en total [...]. También tengo algo de yerba, no mucho, unas 17 hectáreas [...]. Este cuadro de mandioca está parejo, lo elegí porque es linda tierra para plantar, era un yerbal viejo, antes elegían la mejor tierra para plantar, así que ahí limpié para la mandioca. [...] Serán unas 2 hectáreas este cuadro de mandioca, y después entre la yerba, serán unos 10 también. [...] Las ramas son todas mías. Las guardé allá en el pinal. [...] Estas que están acá plantamos en julio, pero vamos a sacar todo en enero- 
febrero, porque ahí esa quebrada si llueve mucho se pudre todo. La que dejamos para rama es la que está plantada ahí en lo alto, más arriba. (Conversación con un productor en la chacra, Gobernador Roca, diciembre del 2016)

Los cultivos de mandioca son anuales, mientras que los de yerba y pino son plantaciones perennes. La importancia de la diferencia entre los ciclos de cada cultivo radica en que, cuando los pinos y la yerba aún son bajos, los productores pueden sembrar la mandioca entre ellos como una forma de reducir el uso de mano de obra y herbicidas para controlar malezas, aspecto del ordenamiento del ambiente que se vincula con la vegetación copartícipe bajo la forma de consociados (cultivos que se plantan intercalados). El hecho de que los productores suelan plantar la mandioca de modo consociado con el pino y la yerba, por otra parte, limita las posibilidades de mecanización, que en los países vecinos de Paraguay y Brasil utilizan de modo extendido, logrando mayores niveles de rentabilidad en los productores más capitalizados.

En los dos testimonios anteriores predominan las dimensiones sensoriales, en las descripciones de Julio y Alejandro acerca de sus chacras — se refieren a plantas grandes que cocinan lindo, cuadros parejos, tallos gruesos, yerbales viejos, tierra linda-. Si bien la plantación de mandioca se ordena por criterios diferenciales (la integración en la huerta y la asociación con los pinos y la yerba respectivamente), ambos productores consideran un aspecto de atención privilegiada la altura del terreno - las quebradas y lo alto-, que es vital en el mantenimiento de los tallos necesarios para la propagación al año siguiente o a los dos años, debido a que las intensas lluvias producen anegamientos que afectan las raíces y ramas.

Las percepciones experienciales sobre las pendientes a las que se refieren los productores se vinculan con los recursos culturales disponibles para tal efecto (Rockwell 2005). Como puede verse a continuación, en el testimonio de Roberto y Darío, los técnicos enfatizan la importancia de la sistematización o trabajo con el suelo mediante el trazado de niveles y curvas, y reconocen que esta depende de instrumentos que los productores (como Julio y Alejandro en los testimonios anteriores) no tienen disponibles. Sin embargo, los técnicos señalan que el equipamiento no es el único elemento, ya que el ordenamiento del ambiente depende fundamentalmente de las prácticas culturales - preparación de cubiertas verdes, terrazas y camellones-, que los productores no realizan habitualmente. La idea de que la mandioca es un cultivo que conlleva numerosas “prácticas culturales” (limpieza del terreno, control de malezas, etc., que se realizan manualmente) es el fundamento de la heterogeneidad en los modos de hacer de los agricultores, que los técnicos reconocen como valiosos. Sin embargo, 
a la vez proponen la incorporación de tecnología y ciertos procedimientos estandarizados, reactualizando una organización jerárquica del conocimiento:

Roberto: estas son labores culturales que cuesta mucho hacerle entender al productor, [...] que con un camellón así, vos estás frenando el agua para que no te lleve el suelo, los nutrientes.

Darío: porque el problema de Misiones, además que son suelos viejos, es la erosión por lluvia. [...] El 95\% de la erosión ocurre por gotas de lluvia, acá llueven 2.000 milímetros anuales. Pero mentalizar al productor que haga distintas técnicas culturales para disminuir la erosión es complicado. Hay que hacer distintas cosas: primero que el suelo tiene que estar cubierto todo el tiempo [...], esa cubierta verde impide que la gota pegue. Pero como va a seguir lloviendo, se arman terrazas, camellones, porque necesitas cierto nivel de pendiente para que escurra el agua [...]. Por eso se recomienda plantar con curvas de nivel, y cortando la pendiente. [...] cuando se habla que tenés $5 \%$ de pendiente, es que desciende 5 metros en 100 metros; se mide con un aparato [...]. Si no tiene el aparato se tiene que acercar al INTA, nosotros vamos y medimos, no lo podemos prestar porque es muy caro pero se mide en un ratito. Lo que pasa es que la gente no lo pide. (Conversación con técnicos en estación experimental del INTA)

El clima es el desafío principal en el trabajo humano de ordenamiento del entorno en lo que hace a la conservación de simientes de mandioca en Misiones. Rival y McKey (2008) estudiaron cómo las estrategias de las unidades domésticas para preservar las variedades en Guyana incluían el intercambio de ramas entre parientes, vecinos y amigos, mostrando de qué manera el reconocimiento del origen de los esquejes (clones) a lo largo de los años era parte de la memoria social de las redes interfamiliares que se expresaban materialmente a través de prácticas agrícolas. Pero las redes tienen como condición la reciprocidad, que depende de la habilidad de poder guardar la propia simiente para intercambiarla, lo que en el caso de Misiones implica prevenir los ataques de heladas y lluvias, y contar con las ramas-semilla para dar y recibir:

Juan: ¿no se le murieron este año ramas por la helada? Está bien resguardado.

Alejandro: nosotros somos baqueanos, hace años que guardamos. Sabemos la que sirve o no sirve antes de guardar. Miramos que madure bien, y le tapamos para la helada con caña si está en el campo, debajo de los pinos ni tapamos. Hay que guardar cuatro o cinco veces más de lo que uno va a plantar, porque algunas tienen los ojitos lastimados. Hay que picar y elegir la parte más linda. Se le sacan las dos puntas, se despunta con el machete. Le dejo tres o cuatro ojitos. 
Juan: esas son las yemas... y ¿ustedes ponen dos o una en cada lugar?

Alejandro: una nomás, si no sale muy apretada. (Conversación con un productor y un técnico en la chacra, Gobernador Roca, diciembre del 2016)

En nuestro trabajo de campo pudimos constatar que los aprendices intervienen tempranamente en ciertas tareas de conservación de simientes, como el corte de ramas y su correspondiente resguardo: los niños de cinco o seis años ya pueden participar activamente porque saben qué tamaño deben tener los esquejes, cuantos ápices y cómo cortarlos en diagonal con el machete, proceso que relata Alejandro en el testimonio anterior, utilizando la analogía de una parte de la planta - en términos del técnico, la yema - con una parte humana: los ojitos. Quienes participan en este trabajo identifican los lugares de la chacra que se han definido en generaciones anteriores para el guardado de ramas — “somos baqueanos, hace años que guardamos”-, y saben cómo se deben cubrir para preservarlos de las heladas. Varios de los manuales elaborados por el INTA aluden a los procedimientos de conservación e implantación de las ramas-semilla, sistematizando prácticas de los productores que han validado y ampliado en sus ensayos experimentales, y traduciéndolas luego a un lenguaje técnico-científico.

Otra cuestión importante que se vincula con el ordenamiento del ambiente en función del suelo y el clima es la fertilización: aquí se encuentra una de las líneas principales de trabajo de los técnicos en el INTA en los últimos años, centrada en los ensayos sobre el uso de distintos químicos para mejorar el rendimiento de la mandioca en suelos degradados por el uso. Como puede verse en el siguiente testimonio, las relaciones de dominio propias del ámbito de CyT son puestas al servicio de la producción intensiva del cultivo, y se expresan en el reconocimiento de la diferencia entre "lo que la planta y el humano quieren, reproducirse o generar raíces útiles”:

Roberto: este ensayo, por ejemplo, mirá qué alta está la planta y qué raíces chicas que tiene. Es como lo que decimos habitualmente "se fue en vicio”. Porque la planta quiere sobrevivir como especie, quiere reproducirse y para eso necesita el tallo, la flor, el fruto. Las raíces, que nos interesan a nosotros, son para ellas reservorios de nutrientes, no les importan tanto. Entonces nosotros sabemos que si acá dosificamos mucho con nitrógeno, por ejemplo, no sirve. Y cuando encontramos el punto justo de nitrógeno repetimos, en distintos tipos de suelo; así sabemos bien cómo funciona. (Conversación con técnico en la estación experimental del INTA, marzo del 2017)

La fertilización tradicional, basada en relaciones de confianza, consiste en dejar en barbecho los terrenos (denominados capueras), y se observa en el 
siguiente testimonio de Alejandro, donde menciona que este método permite que la planta "descanse" y "se cure" a sí misma. La efectividad que los productores misioneros otorgan a las prácticas de barbecho explica el escaso uso de fertilizantes químicos y de rotaciones de cultivo propuestas por los técnicos: si bien últimamente estos sugieren intercalar mandioca con maíz, en general, los productores prefieren una recuperación del terreno a partir de la capuera, que les resulta eficaz y utilizan desde hace generaciones. También se han desarrollado de modo reciente asociaciones de productores orgánicos como la que integra Pablo, que realizan la nutrición de la tierra y ordenan la interacción con microorganismos (sobre los que volveremos enseguida) con métodos alternativos:

Alejandro: mi papá plantaba otras variedades, una que le decían azul y la blanquita común. Dos clases parece que había, tres nomás. Y esas pestes no había nunca antes. Y eso porque ahora se empezó a plantar seguido. Yo abandoné un par de cuadros para que se cubra. [...] Con un año que deja descansar, en capuera, se cura. (Conversación con un productor en su chacra, Gobernador Roca, diciembre del 2016)

Pablo: Nosotros acá hacemos producción orgánica. [...] Mandioca tenemos poco, pero igual todo orgánico. No ocupamos roundup. Con azada, carpida, moto guadaña cuando está muy sucio. Es un trabajo lento, pero se hace. [...] Hace dos años, cuando hice los cursos, aprendí lo malo que es y dejé. [...] Con el curso aprendimos todos los métodos, que el mantillo, que el purín. [...] Acá había todos yerbales viejos, yo planté pinos pero ahora estoy recuperando de a poco con lo orgánico, con capuera, recuperando sin quemar. Acá en la huerta pulverizo con cola de caballo, para hongos, y después con purín de tabaco y alcohol medicinal, ortiga como abono foliar. La hoja de tomate, cebolla de verdeo, se machaca y pulveriza, así espanta naturalmente. Y también hacemos compost, para abono. (Conversación con un productor en la chacra, Gobernador Roca, diciembre del 2016)

La importancia del barbecho dentro de los modos de cultivo de roza y quema ha sido estudiada extensamente por la antropología. En su investigación sobre la mandioca amarga, Guyana, Rival y McKey (2008) abordaron cómo, en el caso de la mandioca, un proceso que resultaba central para la biodiversidad era el manejo de plantas que crecían espontáneamente desde las semillas, ya que al identificar estas plantas que se habían mantenido al resguardo del clima durante años, y dejarlas crecer y madurar, los cultivadores podían evaluar si algún rasgo era positivo, y procedían a la multiplicación clonada vía esquejes. Como se verá en el siguiente apartado, las mandiocas que crecen espontáneamente de semillas son importantes para afrontar las enfermedades, porque al ser resultado de una reproducción sexuada producen nuevas combinaciones de genes que, 
eventualmente, pueden responder mejor a las bacterias y virus que afectan al cultivo desde hace décadas. En ese sentido, este procedimiento combinado de reproducción sexuada y clonada que Rival y McKey (2008) describieron en Guyana es importante porque genera variedades nuevas y el redescubrimiento de otras que habían quedado bajo el barbecho por generaciones: en Misiones no hay estrategias combinadas en las chacras porque las condiciones climáticas lo dificultan, pero en cambio sí se están ensayando en los campos experimentales del INTA.

\section{Relaciones con el entorno no humano: los microorganismos}

Como señalamos al comienzo, los conocimientos vinculados a la identificación de variedades están relacionados con la propagación a través de ramas en las chacras, que puede ser traducida en los espacios institucionales de CyT como un proceso de clonación (como puede verse en el siguiente testimonio de Gastón). Según lo explica Roberto, esta práctica de propagación clonada domésticamente se asocia con la amplitud térmica anual de Misiones, que provoca la caída de los frutos en invierno: la utilización de semillas solo prospera con cuidados especiales, como se hace en las estaciones experimentales del INTA:

Roberto: allá arriba tenés las primeras plantas que conseguimos acá desde semillas. [...] Por ahora nosotros lo que estamos logrando es el cruzamiento sabiendo, botánicamente, cuál es la madre; pero no sabemos cuál es el padre, entonces Mariano, con los marcadores moleculares, está identificando cuáles son los padres. Y ahí vamos a saber recién, de ese material que nació por semilla, cuándo creció y a esas ramas les hagamos una intervención o un trabajo experimental, si rinde mejor que el padre y que la madre. Nuestra zona no se puede hacer producción por semilla porque el fruto, cuando llega el invierno, con temperaturas debajo de los 8 o 10 grados, se cae inmaduro y se muere; en Brasil, en Colombia, donde no hay tanta diferencia climática, la planta tiene otro ciclo, ni siquiera tenés que guardar ramas de la helada, plantas directo. (Conversación con técnicos en la estación experimental del INTA, marzo del 2017)

Como indica Gastón, esta práctica de clonación doméstica redunda en que las enfermedades persistan, porque las nuevas generaciones criadas en las chacras no se renuevan genéticamente:

Gastón: con mandioca estamos teniendo problemas de enfermedades: 
virosis, bacteriosis y algunos hongos. En virosis no hay un producto o tratamiento para sanear. El único método es por laboratorio, in vitro. Por ejemplo el virus del mosaico: [...] si mirás la hoja a contraluz ves unas manchas translúcidas, el problema es que esa parte de la planta no está trabajando, no hace fotosíntesis. Entonces al principio no te das cuenta, pero multiplicación tras multiplicación se va aumentando el estado o grado de infestación, y llega el punto que hay láminas de hojas deformadas [...] Nosotros todavía no lo saneamos, por eso está la idea de usar el método in vitro; se saca una porción muy chica de tejido, generalmente del brote, del ápice, de la punta, y se le pone en un tubo de ensayo con un medio nutritivo de cultivo suficiente para formar una nueva planta. La estaca que nosotros tiramos en la chacra es lo mismo, nomás que en laboratorio lo que se hace es sacar la parte sana, porque en el ápice de la planta se están dividiendo células a tal velocidad, que si les das condiciones de temperatura y humedad adecuadas, ese crecimiento, esa multiplicación es más rápida que la tasa de multiplicación del virus. Así sacamos de laboratorio una planta, de una variedad que queremos, libre de virus. (Conversación con técnico en la oficina del INTA, diciembre del 2016)

En el ordenamiento del ambiente, que implica establecer relaciones con otros no humanos que afectan especialmente a la mandioca, se destacan las virosis, donde los mejoramientos de clones (por reproducción sexuada o in vitro) necesitan de avances en la identificación molecular que, como se deriva de los testimonios de Roberto y Gastón, es aún incipiente en Misiones. La identificación molecular de variedades permite que distintos nombres vulgares sean unificados bajo una misma descripción con base en el ADN, lo que proporciona evidencia de que se trata de "la misma planta con diferente nombre", y a partir de allí elegir los clones más resistentes a enfermedades y reproducirlos de manera segura. De otra forma, como sucede actualmente, los productores descartan una variedad que se ve afectada por virus y eligen otras, pero puede tratarse de la misma aunque no lo adviertan.

Esta ida y vuelta entre las denominaciones vulgares y las científicas aparece en el testimonio de Gastón innumerables veces, quien relata de qué manera el diagnóstico técnico de la virosis suele comenzar a partir de indicios con base en experiencias sensoriales compartidas con los productores - mirar las plantas a contraluz - En el relato del procedimiento de laboratorio para producir in vitro variedades de mandioca libres de virus, aparecen también los procesos de traducción que caracterizan la circulación de los actores sociales por distintos espacios: Gastón elige sinónimos que presenta en sucesión —el brote, el ápice, la punta-y paralelismos - "la estaca que nosotros tiramos en la chacra es lo mismo”-. 
Por otra parte, a diferencia de las identificaciones moleculares que se consideran claves para enfrentar las virosis, en el caso de las bacterias y los hongos, los organismos de CyT realizan trabajos descriptivos que permiten precisar científicamente la especie que afecta al cultivo - la bacteria xanthomona, el hongo fitoftorio, en el siguiente testimonio de Gastón-, pero los procedimientos de ordenamiento del ambiente que proponen los técnicos no difieren de los que realizan habitualmente los productores en espacios domésticos, tales como separar ramas sanas o rotar cultivos:

Gastón: la bacteria que afecta a la mandioca es la xanthomona, se puede tratar con termoterapia, es una enfermedad que afecta los extremos de la planta y va descendiendo hasta que llega a la muerte total del tallo, por eso le llaman muerte descendente. La rocha, que es básicamente para consumo, es muy susceptible a esa enfermedad. Pero nosotros todavía no la tratamos, si tenés un lote infectado, buscas semilla sana para plantar después. [...] En el suelo hay problemas de hongos: ahí estamos tratando en rotación de cultivos: a veces cosechas una planta de ocho raíces y dos están podridas. Esa fuente de inóculo queda seis meses en el suelo, si rotas de cultivo, con una gramínea, un maíz o algo, el hongo no tiene de qué alimentarse, porque el hongo fitoftorio, que es el género que afecta a la mandioca, no se alimenta de maíz, entonces a los seis meses tenés sano tu suelo. Pero acá hacemos mandioca sobre mandioca, no rotamos. (Gastón, técnico de una cooperativa, conversación en oficina del INTA, junio del 2016)

Darío: en las fotos que mostraron en la reunión del clúster, puede ser que sea un micoplasma que haya surgido por estrés, o capaz una rama que se trajo de algún lado. Porque fíjate que las plantas afectadas no son un manchón, como si se hubieran contagiado chinches, por ejemplo, sino por líneo. Entonces es algo que estaba en las ramas que plantaron. (Conversación con dos técnicos en la estación experimental del INTA, marzo del 2017)

De acuerdo con el testimonio de Darío, las experiencias visuales les permiten a los técnicos diagnosticar enfermedades, aunque también ponen en juego las percepciones con la información y denominación genérica proveniente del ámbito de la CyT —que los productores generalmente no tienen-. La relevancia de los espacios asociativos como el clúster radica en que posibilita este tipo de intercambios: conversaciones sobre hallazgos en las chacras, ante los que pueden adoptarse finalmente las mismas respuestas domésticas a las que los productores están habituados, pero tras poner en juego las observaciones entre distintos concurrentes al evento asociativo, con distintas experiencias en el cultivo. 


\section{Conclusiones}

En este trabajo me propuse analizar los procesos de articulación de conocimientos prácticos y científico-técnicos en torno a la mandioca, en contextos rurales interculturales de Misiones (Argentina). En términos conceptuales, me referí a un debate antropológico que ha planteado la relación entre conocimiento y cultura, cuestionando los contrastes entre ámbitos formales e informales, el pensamiento abstracto y el concreto, lo tradicional y lo moderno, la expresión oral y escrita, así como la idea de que las culturas son totalidades homogéneas, en que las prácticas sociales se corresponden con modos de pensamiento y cosmologías inconmensurables.

En la producción de conocimiento sobre el cultivo que se desarrolla cotidianamente en las chacras de indígenas y criollos, en ámbitos asociativos y de CyT, analicé cómo la sociabilidad técnica implica un redescubrimiento guiado, en el que la información se vuelve conocimiento, con base en la participación en actividades con aquellos más experimentados. Procuré mostrar qué conocimientos concretos se producen en el ordenamiento del ambiente destinado a proteger el crecimiento del cultivo, señalando que la identificación de variedades, el suelo, el clima y los microorganismos son las dimensiones principales que se ponen en juego. Asimismo, mencioné de qué manera las experiencias sensibles tienen lugar incluso en los espacios de CyT (para detectar virosis, por ejemplo), que las conversaciones sobre las tareas son fundamentales para traducir expresiones de un ámbito a otro (en descripciones sobre el uso de maquinaria que se ponen en común en el clúster, entre otras) y que la información sistematizada por medio de la escritura también está presente en las chacras (en manuales y ensayos que se realizan en conjunto, etc.).

El principal hallazgo se vincula con lo que se puede llamar, a modo de conclusión, "el problema de las variedades". Como lo he dicho, en el ordenamiento humano del ambiente para la producción de mandioca, los conocimientos incluyen la sistematización de lo que se sabe del cultivo mismo, pero también de los otros no humanos que inciden en su crecimiento. Sin embargo, esos conocimientos no se ubican en un plano equivalente: el problema de las variedades es tal porque genera un encadenamiento con otras problemáticas.

Dado que la mandioca es un cultivo multipropósito, la identificación y selección de variedades es un problema central porque define qué, cómo y cuándo se va a plantar; qué tipo de producto se podrá obtener, con qué rendimiento y resistencia a enfermedades. Estas decisiones se relacionan con el conocimiento disponible en chacras, asociaciones y espacios de CyT, y es allí donde el "problema 
de las variedades” emerge en toda su magnitud. Al reconstruir las variedades tradicionales que los productores añoran, las circulaciones de ramas de mano en mano para encontrar las mandiocas más ricas o con más almidón, las técnicas de conservación de las ramas-simiente, los armados de colecciones en estaciones experimentales, los trazados de curvas, las técnicas de saneamiento de bacterias y hongos o los trabajos de identificación molecular, se evidencia que "ponerse de acuerdo" sobre qué tipo de mandioca se está plantando es clave para todos los actores. Esta es una cuestión que está en el trasfondo de los encuentros en todos los espacios de sociabilidad técnica, aunque no sea formulado explícitamente como tal.

"Ponerse de acuerdo" respecto de las variedades enfrenta varias dificultades que, retomando el debate acerca del diálogo de saberes y las mediaciones sociales, se puede resumir en una más relevante que las otras, y que se vincula con los múltiples sentidos que asume la clonación de mandioca en Misiones. En sus versiones domésticas, la reproducción mediante la conservación de ramassemilla permite conservar las variedades que se consideran valiosas para reproducción en la propia chacra, y a la vez posibilita establecer redes de reciprocidad en las cuales se pueden obtener otras mejores de vecinos y conocidos. En cambio, para los organismos de CyT, la clonación doméstica y la circulación informal de ramas son claves en la "confusión” y la persistencia de enfermedades; por ello, los técnicos apuestan a la genética para identificar molecularmente y, en el futuro, producir clones libres de enfermedades y de mejores rendimientos.

Estos múltiples sentidos sobre la clonación muestran que el diálogo de saberes y las mediaciones sociales tienen aristas de conflicto específicas, vinculadas con lógicas de producción de conocimiento que en ocasiones pueden coincidir, pero en otras son contradictorias. En este caso, las coincidencias se relacionan con lograr, por ejemplo, mandiocas resistentes a virus endémicos o cultivares con mayor porcentaje de almidón y menor ACN. Las divergencias están dadas en que los productores prefieren diversificar variedades para tener diferentes opciones de uso final y rendimiento, aun cuando esto implique perder rigor identificatorio. Por su parte, para los técnicos el principio orientador del conocimiento es estabilizar variedades y organizar la producción de las chacras, en torno a ciertos clones identificados molecularmente y preferidos por sus características químicas y fisiológicas. 


\section{Referencias}

Altenfelder, Marilena. 2016. "Na roça com os Pataxó: etnografia multiespécie da mandioca na aldeia Barra Velha do Monte Pascoal, Sul da Bahia”. Tesis de Doctorado, Universidade de São Paulo, São Paulo.

Bartolomé, Leopoldo. 2007. Los colonos de Apóstoles: estrategias adaptativas y etnicidad en una colonia eslava en Misiones. Posadas: Universidad Nacional de Misiones.

Bartolomé, Miguel. 2009. Parientes de la selva. Asunción: Centro de Estudios Antropológicos de la Universidad Católica Nuestra Señora de Asunción.

Bourdieu, Pierre. 2002. La distinción. Criterios y bases sociales del gusto. Buenos Aires: Taurus.

Cowan, Carlos. 2013. "Laberintos de la emancipación. Reciprocidad y conflicto entre agentes de promoción social y dirigentes campesinos”. Revista de Antropología Social 22: 287-312.

Da Silva Noelli, Francisco. 2004. "La distribución geográfica de las evidencias arqueológicas guaraní”. Revista de Indias LXIV (230): 17-34.

Ellen, Roy. 2004. "From Ethno-Science to Science or what the Indigenous Knowledge Debate Tells us About how Scientists Define Their Project”. Journal of Cognition and Culture 4 (3): 409-450. DOI: 10.1163/1568537042484869.

Emperaire, Laure y Nivaldo Peroni. 2007. "Traditional Management of Agrodiversity in Brazil. A Case Study of Manioc”. Human Ecology 35: 761-768. DOI: 10.1007/s10745-007-9121-x.

Galafassi, Guido. 2008. "El Movimiento Agrario Misionero en los años setenta. Protesta, movilización y alternativas de desarrollo rural”. Revista Herramienta 38. Consultado el 8 de junio del 2018. https://herramienta.com.ar/articulo.php?id=600.

Gallero, María Cecilia. 2013. “Agroindustrias familiares en misiones. Fábricas de ladrillo y almidón de mandioca de alemanes-brasileños (1919-2009)”. Población y Sociedad 20 (1): 41-75.

Gorosito, Ana. 2010. "Los guaraníes de Misiones en la mirada de cronistas y antropólogos”. En Movilizaciones indígenas e identidades en disputa en Argentina, editado por Silvia Hirsch y Gastón Gordillo, 79-100. Buenos Aires: Crujía.

Gras, Carla y Valeria Hernández. 2009. La Argentina rural. De la agricultura familiar a los agronegocios. Buenos Aires: Biblos.

Ingold, Tim. 2002. The Perception of the Environment. Londres: Routledge.

Instituto Nacional de Tecnología Agropecuaria (INTA). 2017. “Qué es el INTA”. Consultado el 28 de junio del 2017. www.inta.gob.ar.

Instituto Nacional de Tecnología Industrial (INTI). 2017. “¿Conocés el INTI?”. Consultado el 28 de julio del 2017. www.inti.gob.ar.

Lave, Jane y Etienne Wenger. 2007. Situated Learning: Legitimate Peripheral Participation. Cambridge: Cambridge University Press.

Ministerio de Agricultura, Ganadería y Pesca. 2015. Asistencia integral en sistemas de gestión de calidad y planificación en la Agroindustria de la Mandioca de la provincia de Misiones. 
Fase II. Ciudad Autónoma de Buenos Aires: Ministerio de Agricultura, Ganadería y Pesca.

Ministerio de Educación de la Nación. 2015. Con nuestra voz cantamos: escritos plurilingües de docentes, alumnos, miembros de pueblos originarios y hablantes de lenguas indígenas. Ciudad Autónoma de Buenos Aires: Ministerio de Educación de la Nación.

Montesinos, Camila y Miguel Altieri. 1991. Status and Trends in Grass-Roots Crop Genetic Conservation Efforts in Latin America. Santiago de Chile: Clades.

Neves, Delma Pessanha. 2010. "Políticas públicas: mediação e gestão de demandas sociais. Retratos de assentamentos”. Retratos de Assentamentos 13 (1): 171-206. DOI: http://dx.doi. org/10.25059/2527-2594/retratosdeassentamentos/2010.v13i1.70.

Padawer, Ana. 2015. "When Soil is Just Right, it Has to Feel Like This. Peasant Youth in Northeastern Argentina. Experiences and Understanding”. En Phenomenology of Youth Cultures and Globalization, editado por Stuart Poyntz y Jacqueline Kennelly, 95-115. Nueva York: Routledge.

-. 2016. "Apuntes antropológicos sobre conocimiento y desarrollo. Abriendo nuevos interrogantes hacia las políticas de educación intercultural en Argentina”. Estudios en Antropología Social 1 (1): 15-22.

Pujol, Benoit, Françoise Renoux, Marianne Elias, Laura Rival y Doyle McKey. 2007. “The Unappreciated Ecology of Landrace Populations: Conservation Consequences of Soil Seed Banks in Cassava”. Biological Conservation 136: 541-551. DOI:10.1016/j.biocon.2006.12.025.

Rival, Laura. 2001. "Seed and Clone: The Symbolic and Social Significance of Bitter Manioc Cultivation”. En Beyond the Visible and the Material, editado por Laura Rival L. y Neal Whitehead, 57-80. Oxford: Oxford University Press.

Rival, Laura y Doyle McKey. 2008. “Domestication and Diversity in Manioc”. Current Anthropology 49 (6): 1119-1128. DOI: 10.1086/593119.

Rockwell, Elsie. 2005. "La apropiación, un proceso entre muchos que ocurren en ámbitos escolares”. Anuario de la Sociedad Mexicana de Historia de la Educación 2004-2005 1: 28-38.

Schiavoni, Gabriela. 2015. “Familiarizar y refamiliarizar. Los alimentos en acción”. Ponencia presentada en la XI Reunión de Antropología del Mercosur, Montevideo, 30 de noviembre-4 de diciembre.

Sousa Santos, Boaventura de. 2003. Crítica de la razón indolente: el desperdicio de la experiencia. Bilbao: Desclee de Brouwer.

Toledo, Víctor y Narciso Barrera-Bassols. 2008. La memoria biocultural: la importancia ecológica de las sabidurías tradicionales. Barcelona: Icaria.

Unidad para el Cambio Rural (UCAR). 2015. Asistencia integral en sistemas de gestión de calidad y planificación en la agroindustria de la mandioca de la provincia de Misiones. Fase II. Proyecto de Asistencia Integral para el Agregado de Valor en Agroalimentos. Ministerio de Agricultura, Ganadería y Pesca. Documento mimeo. 